\title{
EMPRESARIALISMO Y GRANDES PROYECTOS URBA- NOS: ANÁLISIS COMPARATIVO DE PUERTO MADERO EN BUENOS AIRES Y LA LOMA EN BARRANQUILLA*
}

ENTREPRENEURSHIP AND BIG URBAN PROJECTS: COMPARATIVE ANALYSIS OF PUERTO MADERO IN BUENOS AIRES AND LA LOMA IN

BARRANQUILLA

\section{ANGELY MARTÍNEZ GIRÓN **}

\section{R E S U M E N}

En el marco de la gestión empresarial para el desarrollo urbano, el rol del Estado se ha visto supeditado a las lógicas propias del mercado global, las transformaciones urbanas, la potencialización de ciudades como polo de desarrollo e intervención económica y como espacios atractivos para el turismo mundial. Estos procesos se encuentran íntimamente ligados a los flujos del capital y a sus preferencias de localización. Los efectos de este proceso de localización de capitales no se han hecho esperar, estamos frente a ciudades donde no existe sentido de lugar, donde se homogeniza el paisaje urbano y aumenta de forma creciente la fragmentación. Un aspecto característico de este proceso ha sido la generación de grandes proyectos de renovación urbana, especialmente en áreas centrales que con el crecimiento urbano sufrieron un fuerte proceso de marginalización, pero que, conservaron sus ventajas espaciales en términos de accesibilidad, infraestructura y localización, lo cual las convierte en potenciales áreas de oportunidad.

PALABRAS CLAVE: Empresarialismo, G.P.U, privatización, mercado, globalización.

\section{A B S T R A C T}

In the framework of business management for urban development, the role of the State has been subordinated to the logic of the global market; urban transformations, the potentialization of cities as a pole of development and economic intervention and as attractive spaces for world tourism. These processes are closely linked to capital flows and their location preferences. The effects of this process of capital location have not been expected, we are facing cities where there is no sense of place, where the urban landscape is homogenized and increasingly increases fragmentation. A characteristic aspect of this process has been the generation of large urban renewal projects, especially in central areas that suffered a strong process of marginalization with urban growth, but that retained their spatial advantages in terms of accessibility, infrastructure and location. which makes them potential areas of opportunity.

KEYWORDS: Entrepreneurialism, G.P.U, Privatization, Market, Globalization.

\footnotetext{
"Este artículo de investigación es resultado del curso "Gobierno de la Ciudad", en el marco de la maestría de investigación en Estudios Urbanos de la Flacso-Ecuador 2015-2017.

** Maestra de investigación en Estudios Urbanos. Facultad Latinoamericana de Ciencias Sociales Sede Ecuador, Quito - Ecuador. Avenida Diego de Almagro. Código Postal: 170201, Quito - Ecuador. Correo eletrónico: ange.martineez@hotmail.com
} 


\section{INTRODUCCIÓN}

Durante las últimas cuatro décadas, la ciudad y su paisaje urbano han sufrido numerosas transformaciones, la mayoría ligadas a los procesos políticos, sociales y económicos, entre ellos, el más influyente ha sido el tránsito de una economía manufacturera e industrializada a una economía financiera y de servicios altamente globalizada. Este proceso si bien ocurrió primero en las ciudades del norte global, con el tránsito del fordismo y la sociedad industrial a la era informacional y financiera, se expandió con notable intensidad a América Latina. En este escenario, sugieron nuevos modelos de gestión pública, que en gran medida apuntaban a responder a las problemáticas que se agudizaron con el crecimiento acelerado de la urbanización. No obstante, fue solo hasta la década de los ochentas que se puso de manifiesto el tránsito hacia un nuevo modelo de gobernanza ligado a la gestión empresarial.

Corral (2010) afirma que la planificación urbana se ve fuertemente convulsionada tras la entrada de los modelos de gobernanza neoliberal en América Latina. En este contexto desaparece el rol del Estado como garante del desarrollo urbano, especialmente en lo relacionado con la provisión de bienes, servicios e infraestructura pública. Este escenario en el que el Estado cede su rol determinante como garante y asume el rol de promotor del desarrollo urbano se inscribe en el tránsito hacia el modelo de gobernanza empresarialista de gestión pública (Rofman, 2006).

La prioridad de este nuevo modelo de gobernanza, resulta ser la administración de los recursos económicos del Estado y el restablecimiento de la dirección financiera del estado, principalmente en relación a ingresos y gastos innecesarios que contribuyeron ampliamente a la distorsión del crecimiento económico (Aguilar, 2009). De igual forma este nuevo modelo de gestión impuso una nueva forma de planificar el territorio, que estaba ligada al impulso de la economía y el desarrollo urbano, con el objetivo de potenciar la inversión tanto extranjera como nacional y de fomentar la inserción de capitales privados.

Esta gestión pública empresarial influyo directamente en la reordenación del modelo administrativo del Estado. En este orden de ideas varios autores detentan como factores determinantes para dar paso a la gestión empresarial, las crisis económicas y sociales que 
enfrentaban principalmente los estados Unidos, los países europeos continentales y América Latina (Aguilar, 2009). Este argumento es respaldado por Harvey (1989) quien destaca diversas causas de origen, entre ellas "la crisis, la recesión de 1973, la desindustrialización, la perdida estructural del empleo" (p.8).

Estos factores conllevaron a políticas de austeridad fiscal en el plano de lo nacional y lo local, así como a una creciente ola de neoconservadurismo y un fuerte llamamiento (aunque a menudo más en la teoría que en la práctica) a la racionalidad del mercado y la privatización. Estos aspectos proporcionan un telón de fondo para entender por qué tantos de los gobiernos urbanos, a menudo de muy diferentes tendencias políticas y armados con el poder judicial y el poder político, han tomado una amplia dirección similar" (Harvey, 1989, p. 8).

En este contexto, la ciudad paso a jugar un rol primordial como escenario propicio para la acumulación de capitales (Pradilla, 2014), como capital fijo, ya que si bien no produce objetos en sí, se convierte en el espacio apropiado para la inversión y acumulación de capitales. (Harvey 1989). Por tanto, la ciudad se encuentra inmersa en la dinámica de la competencia interurbana, en la que se busca establecer el mayor atractivo a las ciudades y potenciar su imagen como escenarios para la inversión y acumulación de capitales (Harvey, 1989, p.10).

Este nuevo tipo de gestión urbana empresarialista, derivó en políticas de competencia urbana, city marketing, procesos de privatización del desarrollo urbano o como le denomina De Mattos (2008) "mercantilización de la dinámica urbana” (p.36), que en general, son dinámicas propias de una misma lógica de gestión urbana, en la cual el Estado disminuye sus funciones. De esta forma, se retrae de sus obligaciones en la dirección del desarrollo urbano y cede el terreno a el sector privado, a quien entrega la potestad para definir el devenir de las ciudades (Lungo 2005), aunque claramente el sector público no sea el mayor beneficiario- vaciando de contenido y significado la esencia de algunos lugares identitarios para la ciudadanía. A la luz de lo anterior, las ciudades han jugado un rol principal, especialmente en relación a la importancia que tiene para este nuevo tipo de gestión urbana el territorio y su reconfiguración, muy ligada a la competencia y el desarrollo de la economía mundial, especialmente en relación al tránsito hacia una economía de servicios, altamente especializados. 
No obstante, el sello distintivo de este modelo de gestión empresarial han sido los grandes proyectos de renovación urbana (G.P.U.), que se caracterizan por la recuperación de zonas urbanas deterioradas, pero con características especiales en cuanto a la localización, la calidad de los emplazamientos urbanos aledaños, bajos costos de renta del suelo y buenas condiciones de accesibilidad:

Los grandes proyectos urbanos se orientan a la transformación funcional y física de áreas estratégicas, que habían quedado relegados por el declive de los usos funcionales otrora dinámicos en la etapa industrialista, para adaptarlos a los nuevos requerimientos de acumulación y consumo que plantea el capitalismo en su fase actual. (Cuenya \& Corral, 2011, p. 28).

El presente artículo se propone indagar en torno a los roles y estrategias que ejecutan los gobiernos locales para la construcción de grandes proyectos urbanos en América Latina. Para este propósito se ha planteado metodológicamente un análisis comparativo, que aborda dos unidades de análisis: por un lado Buenos Aires y por otro Barranquilla, la característica transversal de estas dos unidades de análisis es su ventaja localizativa, determinada por ubicación costera; Buenos Aires entre el Rio de la Plata y el Riachuelo; y Barranquilla entre el Rio Magdalena y el Mar Caribe, en este mismo escenario los dos megraproyectos analizados: Puerto Madero y La Loma, apuntan a la reactivación económica de zonas portuarias en desuso.

"Las áreas litorales han constituido, a lo largo de la historia, un ámbito favorable para el asentamiento de la población por las actividades humanas. En 2014 la población urbana de America Latina y el Caribe alcanza casi los 500 millones de habitantes (UN-DESA, 2014：25),considerándose la región del mundo en desarrollo con un mayor porcentaje de población urbana (PNUMA, 2010: 27). Además, por razones históricas, el origen de la expansión urbana de esta región se sitúa en la franja litoral. (Barragán, 2012, p.12). Actualmente son 364 las ciudades y aglomeraciones costeras las que tienen algún tipo de infraestructuras portuarias asociadas, lo que supone el $87 \%$ de todas las Ciudades y aglomeraciones costeras. En cuanto a la población, 165 millones de personas viven en estas CACs, por lo que el 91\% de la población urbano costera (en ciudades mayores a 100.000 habitantes) está asociada de alguna forma a este tipo de infraestructuras. (Barragán y Andrés, 2016, pp. 130-142).

Así pues, este análisis busca dar respuesta a la pregunta: ¿Que roles y estrategias ejecutan los gobiernos locales en la construcción de mega proyectos urbanos? Lo anterior a partir de un análisis de tipo comparativo, haciendo uso de técnicas de revisión de bibliografía especializada y fuentes de prensa. Para el caso de Puerto Madero las fuentes corresponden a resultados de investigaciones; y para el caso del proyecto La Loma, proyecto que aún se 
encuentra en la fase inicial y dado el acceso limitado a bibliografía especializada, se analiza información oficial de la alcaldía de Barranquilla, fuentes de prensa e investigaciones preliminares sobre el avance del proyecto (Terán, 2016).

La hipótesis que se plantea para este análisis está íntimamente relacionada con la literatura especializada en relación al tema de los G.P.U y al empresarialismo urbano, y presenta un marcado carácter deductivo, que suscita inferencias a partir de la teoría hacia los casos: En las ciudades de América Latina los G.P.U se caracterizan por la recuperación de centralidades urbanas en estado de deterioro, pero que conservan ventajas especiales en relación a: localización, accesibilidad, bajo costo de inversión y alta posibilidad de ganancia, convirtiéndoles en espacios del capital privatizados y excluyentes. En este escenario, los gobiernos locales juegan un rol central que no solo promueve la inversión privada, sino que a su vez otorga las concesiones para la transformación de usos del suelo, los marcos legales para la expulsión de la población residente en la zona de intervención (de ser el caso) y la potencialización de la inver- sión en infraestructura pública, pasando de ser un actor garante a convertirse en un promotor (Cuenya, 2011; Corral, 2009).

Para dar cuenta de lo planteado, el artículo está estructurado en tres acápites: en un primer momento, se propone un acercamiento al tema de la gestión pública empresarial y los grandes proyectos urbanos (G.P.U) desde la literatura especializada. En un segundo , se expone una contrastación de las características mencionadas, desde los casos del proyecto Puerto Madero en la ciudad de Buenos Aires y el Proyecto La Loma en la ciudad de Barranquilla ${ }^{1}$, determinando así cuales de estas características de la teoría son verificables en estas dos unidades de análisis y que roles y estrategias de actuación jugaron los gobiernos locales en la construcción de los G.P.U; y por último se presenta al lector una conclusión general ligada a la revisión de la literatura especializada y dos conclusiones específicas para cada caso en torno a las actuaciones del gobierno local en la ejecución de los G.P.U.

\footnotetext{
${ }^{1}$ Seleccionadas como unidades de análisis a propósito de sus ventajas localizativas como ciudades costeras y del objetivo común de los gobiernos locales que a través de la ejecución de grandes proyectos urbanos,
}

apuntaban a la reactivación económica del área portuaria. 


\section{DISCUSIÓN TEÓRICA: LOS G.P.U Y EL EMPRE- SARIALISMO URBANO}

En la nueva dinámica capitalista de financiarización económica, es el mercado quien regula y define las transformaciones del espacio urbano y la vinculación de las ciudades a las redes económicas a escala global. La inversión resulta ser un factor importante para explicar el nuevo rol que asumen los gobiernos locales en la construcción de ciudades, principalmente porque el objetivo es impulsarlas como espacios propicios para la inversión capitales fijos-. En esa medida ya no se planifica la ciudad para el beneficio de sus ciudadanos, sino que se vende un producto atractivo para posibles inversores, la ciudad se convierte en mercancía y el gobierno local asume el rol de vendedor/promotor que embellece el producto que oferta. Las actuaciones de los gobiernos locales están determinadas por el modelo empresarial, que a partir del aumento de la inversión en sus territorios, justifica el crecimiento de la ciudad, la modernización en infraestructura, la recuperación económica y la mejora en la calidad de vida (De Mattos, 2008).

El elemento distintivo de estos modelos de gestión pública empresarial, han sido los grandes proyectos de renovación urbana, a partir de los cuales, los gobiernos locales/nacionales en asocio con el sector privado-capital financiero y mercado inmobiliario-, emprenden acciones conjuntas en pro del desarrollo urbano, convirtiendo las ciudades en escenarios privilegiados para la innovación y la competitividad. En este contexto de creciente financiarización del desarrollo urbano, el mercado inmobiliario paso a jugar un rol altamente determinante en la dirección de los procesos de planificación urbana; no obstante esta participación del mercado inmobiliario ha estado vinculada al rol de los gobiernos locales en la promoción de la inversión privada, lo cual ha potenciado la consolidación de espacios del capital (Harvey, 2001), en los cuales prima el desarrollo del lugar por encima del desarrollo del territorio.

Dado lo anterior, resulta importante clarificar qué tipo de acciones pueden catalogarse como proyectos de renovación urbana, para lo cual Lungo destaca: "la recuperación de centros históricos, construcción de sistemas de transporte público masivo, reutilización de antiguas zonas industriales, militares, ferroviarias, portuarias, aeroportuarias, etc.; la rehabilitación de grandes áreas de vivienda degradadas, la construcción de nuevas zonas turísticas o recreativas; etc." (Lungo, 2005, p. 52). Para el caso de Europa y Norteamérica son más frecuentes las 
construcciones de infraestructura urbana (op.cit.).

Empero, autoras como Beatriz Cuenya, proponen que los grandes proyectos de renovación urbana en Latinoamérica, han transformado drásticamente el paisaje de la ciudad y se han enfocado principalmente en la construcción/re-construcción de centralidades urbanas, primordialmente reproduciendo tres tipos de modificaciones que son claves en la revitalización de las centralidades:

Los grandes proyectos urbanos consisten en operaciones de renovación urbana en gran escala que producen al menos tres modificaciones claves en la estructura de la centralidad de las actuales metrópolis: una modificación en la rentabilidad de los usos del suelo; una modificación funcional y físico espacial de áreas centrales estratégicas; y una modificación de los mecanismos de gestión pública. (Cuenya 2011, p.186).

Estas tres modificaciones, según señala la autora, han sido fundamentales en el marco de la economía de la globalización y el avance del capitalismo, convirtiéndose en una herramienta clave para la construcción de un nuevo sentido de lugar, que dota a las ciudades de nuevos "artefactos de la globalización" (De Mattos, 2001, p. 35). Así mismo, estas centralidades urbanas en desuso, representan una ventaja significativa para el constructor y para la ciudad, ya que su condición de bie- nes públicos permiten que la renovación no suponga costos elevados de compra de predios y que a través de la ejecución de obras de infraestructura pública, el gobierno local como promotor urbano pueda potenciar el valor de la zona de intervención a través de recursos públicos destinados a bienes, servicios e infraestructura urbana.

Cabe resaltar que toda aproximación analítica al fenómeno de los G.P.U, debe enmarcarse en el proceso de city marketing. En este aspecto, De Mattos en su texto sobre "Globalización, negocios inmobiliarios y mercantilización", enuncia como este nuevo modelo de gestión pública basado en la "cosmética urbana", selecciona ciertos espacios de la ciudad para convertirlos en icono distintivo de la misma y de esta manera promoverla/venderla ante la inversión extranjera directa (IED). Este proceso de marketing urbano ha potenciado áreas como el turismo, las inversiones extranjeras y el desarrollo de las tecnologías urbanas -Smartcities-. En este fenómeno del city marketing, los grandes proyectos de renovación urbana se consolidan como: "el instrumento básico para la venta de cada ciudad ante los posibles inversores inmobiliarios" (De Mattos, 2008, p. 51).

Este nuevo rol que exhibe la ciudad contemporánea, en la lógica de la gestión 
empresarial, está muy asociado a la transformación del urbanismo europeo hacia finales del siglo XX (Lungo, 2005). Vinculado su vez, a la incorporación de diversos actores para el fortalecimiento de ciertas áreas de la ciudad, desde enfoques: políticos, económicos, culturales sociales y ambientales, tal como lo exponía Harvey desde 1989 (Harvey, 1989). De igual forma, para autores como Lungo, los G.P.U en sus inicios suponían una fuerte contradicción con la planificación tra- dicional, debido a tres razones principales: "realizarse en una temporalidad prolongada, ser una obra pública, aunque exista inversión privada; tener orígenes diversos pero estar guiados por una voluntad e idea compartida por los principales actores urbanos" (Lungo, 2005, p.53). Uno de los principales aportes del trabajo de Lungo (2005) al análisis de los G.P.U, desde un enfoque histórico, es la recuperación de la clasificación por generaciones de G.P.U (cuadro 1).

CUADRO 1. GENERACIONES DE G.P.U.

\begin{tabular}{|c|c|c|}
\hline PRIMERA GENERACIÓN & SEGUNDA GENERACIÓN & TERCERA GENERACIÓN \\
\hline $\begin{array}{l}\text { Caracterizada por tener como } \\
\text { objeto la construcción de } \\
\text { infraestructuras o servicios } \\
\text { urbanos, recuperando y } \\
\text { ampliando el concepto de } \\
\text { "obra pública"; estar basados } \\
\text { en el protagonismo público e } \\
\text { intervención directa del } \\
\text { gobierno central o municipal; } \\
\text { ser concebidos como motores } \\
\text { de la transformación urbana y } \\
\text { recuperación del medio } \\
\text { ambiente; brindar atención } \\
\text { prioritaria al espacio público. }\end{array}$ & $\begin{array}{l}\text { Diversifican sus objetos de } \\
\text { intervención (conformación } \\
\text { de nuevas centralidades, } \\
\text { mejoramiento de zonas } \\
\text { pobres, etc.); romper los } \\
\text { límites geográficos de las } \\
\text { intervenciones tradicionales } \\
\text { llegando incluso a la } \\
\text { periferia; introducir criterios } \\
\text { de rentabilidad económica } \\
\text { incorporando al sector } \\
\text { privado en la gestión. }\end{array}$ & $\begin{array}{l}\text { Grandes proyectos } \\
\text { metropolitanos; concebidos } \\
\text { como motores de desarrollo } \\
\text { para el espacio metropolitano; } \\
\text { promover la recuperación } \\
\text { integral de los centros } \\
\text { históricos, no solo del } \\
\text { patrimonio histórico; } \\
\text { contribuir; transformación de } \\
\text { la periferia interna y creación } \\
\text { de nuevas centralidades. }\end{array}$ \\
\hline
\end{tabular}


En este marco de ideas, los casos de La Loma y Puerto Madero, corresponden a la clasificación de G.P.U de tercera generación, debido a características como: la recuperación de áreas de especial importancia para el patrimonio histórico de la ciudad, el hecho de que los territorios a renovar se presentan como espacios que potencian el desarrollo económico de la ciudad y se convierten en ejes de desarrollo de la región y por último la transformación de la noción de espacios públicos para convertirse en áreas exclusivas de privatización, por medio de procesos de cambio de usos del suelo y aumento de la renta urbana. Los anteriores son aspectos distintivos de los G.P.U, tal como lo evidencia Valenzuela (2013) para del G.P.U Santa Fe en ciudad de México:

Los grandes proyectos urbanos tienen diversos impactos importantes en el territorio (Lungo, 2004, p. 17). Por una parte, se altera el valor del suelo mediante el cambio de usos que generalmente acompaña a un proyecto; se modifican la morfología y las funciones de extensas áreas de la ciudad; y finalmente, se establece un modelo de gestión territorial distinto al tradicional. Estos proyectos son particularmente atractivos para el capital, por su capacidad de generar una valoración exponencial del suelo que eventualmente formará parte de un mercado inmobiliario internacional. (Valenzuela, 2013, p. 102).
Estos grandes proyectos de renovación urbana reflejan las transformaciones socio-territoriales que imponen las lógicas del capital altamente globalizado, es decir los G.P.U, se convierten en la pieza fundamental de los intereses del capital económico y a través de ellos se producen transformaciones en el espacio urbano. Los grandes proyectos de renovación urbana se convierten en el dispositivo característico de la nueva gobernanza empresarial:

En suma, el patrón de producción de
grandes proyectos urbanos -en el
que se conjugan de modo complejo
los principios del urbanismo y del
desarrollo inmobiliario- contiene los
tres rasgos que conceptualmente de-
finen al empresarialismo, según Har-
vey: la alianza entre el sector público
y el sector privado; empleo de una ló-
gica especulativa por parte del sector
público y el privilegio de iniciativas
centradas en el lugar. A esto se aso-
cian otros elementos que también ca-
racterizan la estrategia pública em-
presarial, tales como: el modo corpo-
rativista de tomar las decisiones, así
como también la falta de transparen-
cia en los procedimientos y en las
rendiciones de cuentas. (Cuenya y
Corral, 2011, p.3o).

Estos proyectos focalizan áreas que perdieron su funcionalidad en el entramado urbano, pero que aún conservan ventajas de localización, por lo cual pueden constituirse como pieza fundamental de un proceso de reactivación 
económica de las áreas centrales, históricas o emblemáticas de la ciudad (Corral, 2009, p.4). En este escenario es fundamental entender las actuaciones de los diversos agentes que intervienen en la construcción de estos grandes proyectos, para autoras como Cuenya (2009) podemos identificar 3 tipos de actores:

1. Los actores beneficiados principales: "quienes tienen una incidencia directa en la definición del proyecto y, más allá de sus lógicas particulares de actuación, tienen interés y posibilidad de exigir una participación en los beneficios que se generan con la forma de plusvalías inmobiliarias y/o ganancias empresarias" (p.244). Estos están representados en; los propietarios del suelo, los promotores inmobiliarios, las constructoras, el sector financiero y el Estado o gobiernos locales,

2. Los beneficiarios auxiliares: "que también obtienen ventajas económicas a través de la producción y ejecución de estos grandes proyecto" (p.245). En este grupo encontramos a los grandes estudios de arquitectura, las firmas constructoras, las empresas de servicios de segunda línea y la burocracia pública.
3. Los actores perjudicados:

"que incluyen esencialmente a: a) los habitantes de bajos ingresos localizados irregularmente en los predios donde se desarrollan los proyectos y que pierden su lugar de vida y de trabajo en la ciudad; b) las empresas que todavía desarrollan actividades en el área de implantación de los proyectos, aunque el tipo de usos del suelo que ejercen está en declinación (viejas fábricas de rentabilidad baja, depósitos y silos, partes de empresas ferroviarias, portuarias, aeroportuarias); c) los residentes en las áreas aledañas, que pueden verse afectados por la suba de los valores del suelo y los consecuentes procesos de gentrificación que eso conlleva" (pp. 245-246).

Cabe destacar que en el proceso de ejecución de estos grandes proyectos de renovación urbana, estos tres actores entran en tensión y sus actuaciones entran a determinar el avance de las obras y pueden a su vez suponer la paralización de las mismas (Cuenya, 2009), especialmente cuando los actores perjudicados inician procesos de resistencia. En el siguiente acápite se presentan los casos de estudio: Puerto Madero en Buenos Aires y La Loma en Barranquilla, en los cuales se analizará específicamente el rol y las actuaciones del gobierno local, quienes juegan el rol de beneficiarios principales en el marco de los grandes proyectos de renovación urbana. 


\section{EL CASO DE PUERTO MADERO EN BUENOS AIRES Y LA LOMA EN BARRANQUILLA}

\subsection{Puerto Madero: Buenos Aires}

En la Argentina el proyecto de renovación urbana encarado en las 170 hectáreas del antiguo puerto, constituye un emblemático GPU. En el Plan de Desarrollo Urbanístico de Puerto Madero se exalta no sólo la creación de más espacio público, sino también la importancia de su indudable transformación: esta operación implica una metamorfosis revitalizando un espacio público degradado. Reivindicado así, la gestión privatizadora del Estado neoliberal sin dejar de remarcar la tendencia al deterioro generalizado que significan los desplazamientos de centralidades: "la pérdida de valor de las localizaciones y la sustitución de las actividades prestigiosas por otras menos valiosas, la transformación de los antiguos edificios en viviendas precarias, y la disminución de control social sobre el espacio público. (Garay, 2011, p. 97).

El proyecto Puerto Madero está ubicado en la zona central de Buenos Aires, su ubicación estratégica sobre el Rio de la Plata le ha convertido en un área de interés para el desarrollo de la ciudad. No obstante es en la década de los noventas que el barrio se articula a los planes de reactivación de las zonas portuarias (Ramírez, 2014 Citado En Ramírez, 2017). El proyecto de renovación urbana Puerto Madero abarcaba
170 de las hectáreas del viejo puerto, las cuales serían intervenidas a través de la creación de un plan de desarrollo urbanístico, este plan contemplaba la rehabilitación de espacios públicos degradados, refuncionalizacion edilicia norma de protección patrimonial de 1991- la protección de la imagen de los espejos de agua, la preservación estructural de los galpones, la puesta en valor -e integración paisajística- de las grúas y silos lo que contribuía a preservar y/o poner en valor el espacio, la recuperación del acceso al río y la vista a la costa, la generación de un polo de atracción turística, la reinserción del territorio en el mercado y en el aumento de valor del suelo (Ramírez, 2017).

En este escenario, Puerto Madero se constituyó como una de las estrategias de renovación urbana, más emblemáticas de los últimos 30 años en América Latina. Planteado en un primer momento como una estrategia de recuperación de la dinámica económica, social y cultural del centro y como apuesta para la recuperación del patrimonio histórico de la zona céntrica en Buenos Aires. Puerto Madero apuntó a la revitalización económica y la reducción de la degradación del centro -la cual ya había permitido el avance de pequeñas invasiones (Garay, Wainer, 
Henderson y Rotbart 2013). No obstante, Ramos señala que tras el proceso de renovación el barrio se transformó en un espacio elitizado, un símbolo de poder y dinero; "en su look de primer mundo penetran a veces realidades que recuerdan a problemáticas propias de Latinoamérica (como la proximidad de una villa de emergencia, o las aglomeraciones de puestos de venta informal en la Costanera Sur durante los fines de semana). Pero en la mayor parte de su extensión Puerto Madero luce atractivo y fotogénico, como una estrella de cine llena de glamour" (Ramos, 2009 Citado En Cuenya y Corral 2011, p. 33).

\section{Figura 1. Puerto Madero}
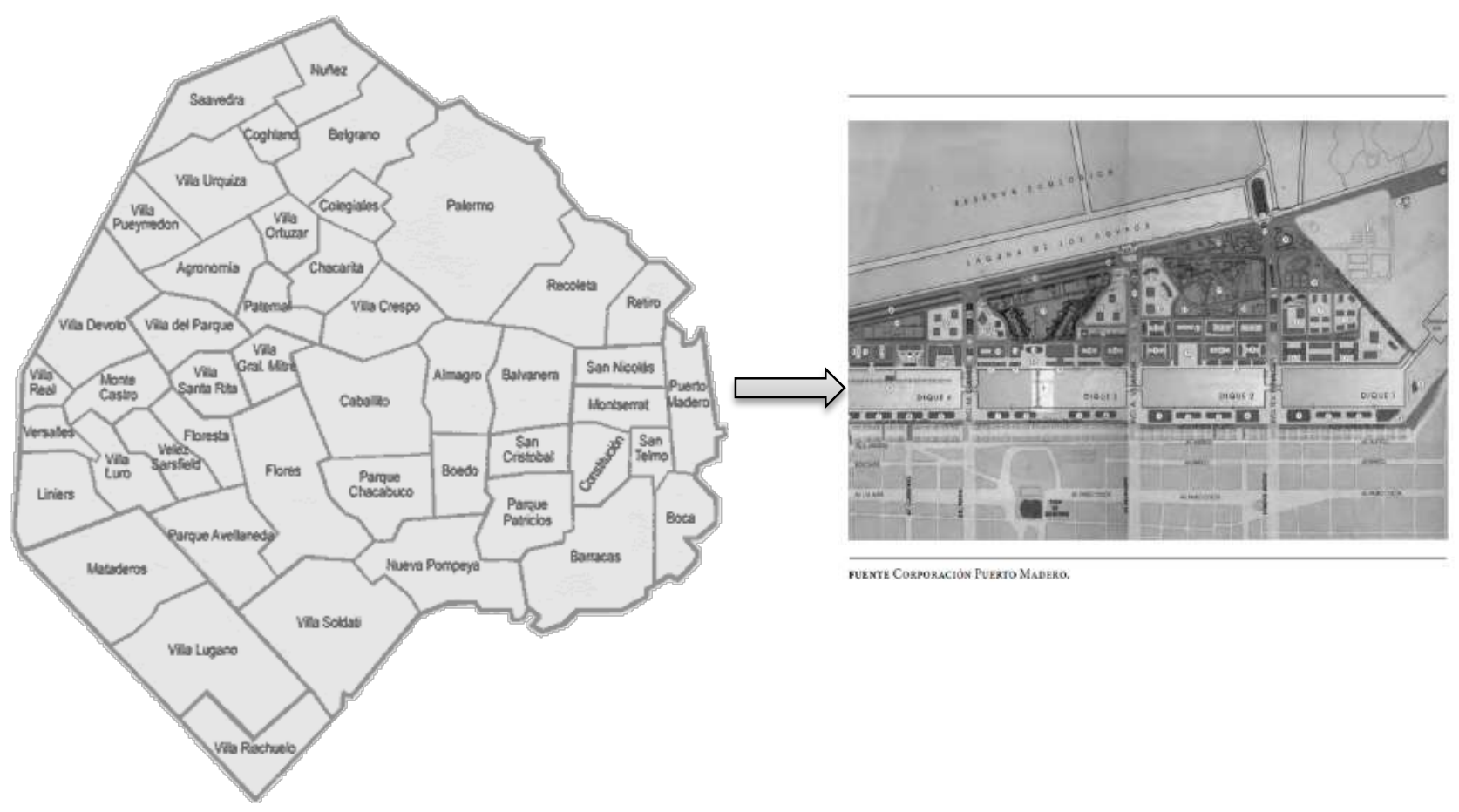

Fuente: http://www.latidobuenosaires.com/mapasmonserratbarriobuenosaires.html; Corral y Cuenya 2011.

A continuación se presentan las diferentes etapas de ejecución del proyecto Puerto Madero (cuadro 1), planteadas por Garay, Wainer, Henderson y Rotbar (2013), en su análisis sobre Puerto Madero. 
CUADRO 1. CRONOLOGÍA PUERTO MADERO

\begin{tabular}{|c|c|c|c|}
\hline Etapa 1. (1989-1992) & Etapa 2. (1993-1995) & Etapa 3 (1996-2000) & Etapa 4 (2001-2004) \\
\hline 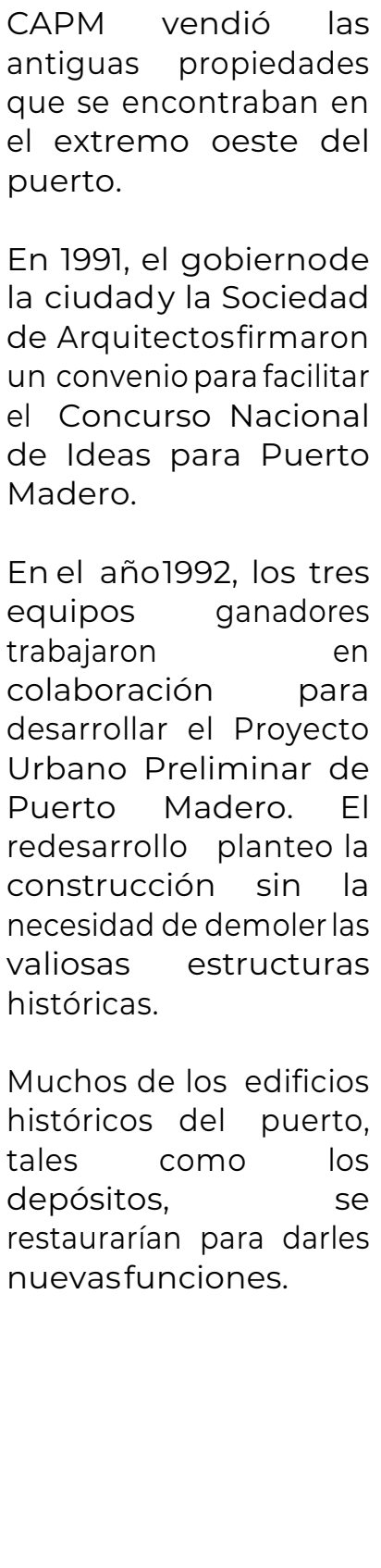 & 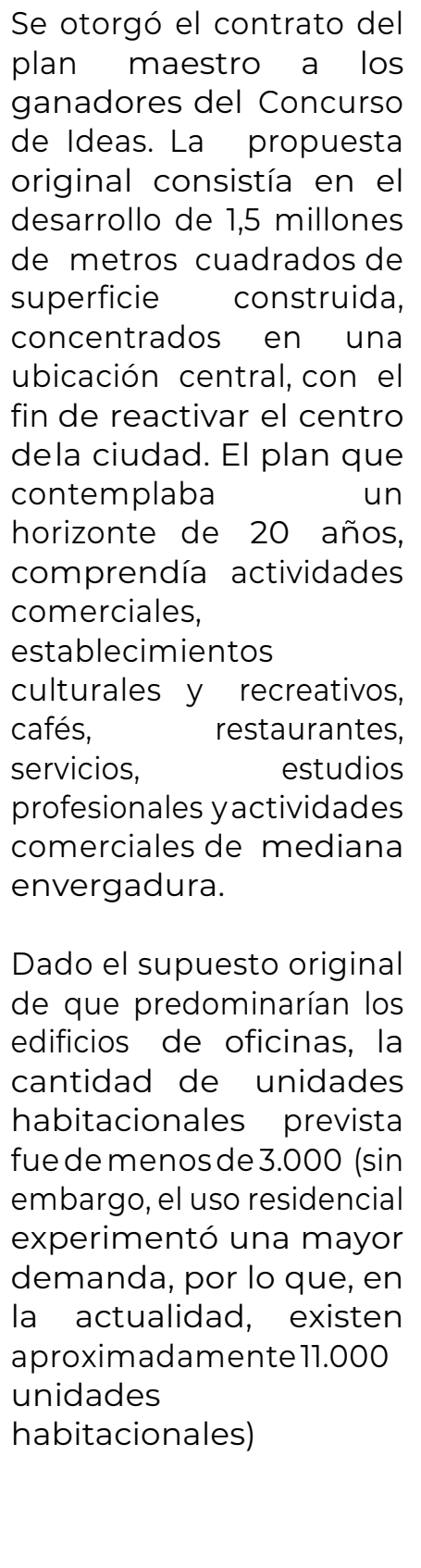 & $\begin{array}{l}\text { Serealizóla mayorparte } \\
\text { de las obras públicas y } \\
\text { los gastos del proyecto } \\
\text { aumentaron en gran } \\
\text { manera junto con las } \\
\text { ventas de terrenos. A lo } \\
\text { largo de esta etapa, el } \\
\text { costo por metro } \\
\text { cuadrado de } \\
\text { construcción no varió } \\
\text { en forma significativa, } \\
\text { yaque osciló entre150y } \\
\text { 300 dólares por metro } \\
\text { cuadradohasta finales } \\
\text { de la década (todos los } \\
\text { precios mencionados } \\
\text { se refieren a dólares } \\
\text { estadounidenses). } \\
\text { En esta terceraetapa,el } \\
\text { perfil de los inversores } \\
\text { había evolucionado de } \\
\text { un grupo pionero } \\
\text { inicial formado por } \\
\text { pequeñas y medianas } \\
\text { empresas a grandes } \\
\text { firmas que invertían } \\
\text { en productos de } \\
\text { eficacia comprobada. } \\
\text { Para el año 2001, } \\
\text { quedaban pocos } \\
\text { terrenos públicos para } \\
\text { vender y la empresa } \\
\text { pública poseía } \\
\text { suficientes activos } \\
\text { líquidos para finalizar } \\
\text { las obras públicas } \\
\text { necesariasparael } \\
\text { proyecto. }\end{array}$ & $\begin{array}{l}\text { De } 2001 \text { a } 2003 \text { yde } 2004 \text { a } \\
\text { la actualidad: el proyecto } \\
\text { sufrió las turbulencias } \\
\text { económicas, financieras y } \\
\text { políticas asociadas con la } \\
\text { crisis fiscal de 2001, } \\
\text { impulsada por la falta de } \\
\text { pago del gobierno respecto } \\
\text { de su deuda externa. Las } \\
\text { ventas de terrenos se } \\
\text { detuvieron. No obstante, } \\
\text { con posterioridad a las } \\
\text { elecciones presidenciales del } \\
\text { año } 2003, e l \text { país retomó las } \\
\text { negociaciones } \\
\text { internacionales, reestructuró } \\
\text { su deudaexterna y mejoró } \\
\text { significativamente sus } \\
\text { condicioneseconómicas. } \\
\text { A medida que los terrenos } \\
\text { disponibles en Puerto } \\
\text { Madero se volvían escasos, } \\
\text { los desarrolladores } \\
\text { recurrieron a las áreas que } \\
\text { rodeaban el centro de la } \\
\text { ciudad a modo de sitios } \\
\text { alternativos para la } \\
\text { inversión. }\end{array}$ \\
\hline
\end{tabular}

Fuente: Garay, Et Al. (2013) . "Puerto Madero Análisis De Un Proyecto". Lincoln Institute Of Land Policy pp. 10-16. 
El proyecto Puerto Madero se clasifica como un G.P.U de tercera generación, debido a sus características tales como: La revitalización de un centro degradado que a su vez se convertiría en el sello del desarrollo metropolitano, la tendencia a la recuperación de zonas patrimoniales y la fuerte vinculación del sector privado como actor determinante en la construcción de edificios de oficinas, viviendas y emprendimientos que potenciarían la inversión en la zona aledaña a los edificios patrimoniales recuperados. Todo esto acompañado de una fuerte alianza público-privada, representada en la creación de la Corporación Puerto Madero, bajo esta modalidad de alianza el Estado abandero una fuerte inversión para la recuperación de la infraestructura urbana en la zona de intervención. En este caso y referidos al tema de análisis sobre la actuación del estado, el G.P.U tiene una amplia participación del actor estatal, especialmente en lo relacionado con el objetivo de recuperar el área para potenciar la imagen de la ciudad y constituir el lugar como una zona atractiva para la inversión en diversas áreas. Sin embargo y ya que el interés central de este análisis también pretende evidenciar que características de los G.P.U se presentan en el caso Puerto Madero, se presenta a continuación un análisis elaborado por Manuela
Corral (2009), en relación dos (2) características centrales de la literatura especializada que se manifiestan en el caso del G.P.U Puerto Madero:

\section{Transformación del suelo y espa-} cios de capital: Para el Caso de Puerto Madero, Corral expone cómo el G.P.U obedece a una de las características fundamentales de los grandes proyectos urbanos, tal como es "la transformación de los usos del suelo y la reconversión de espacios degradados, con el fin de incorporarles a las lógicas de la economía mundial, transformando sus geografías a propósito de consolidarlos como espacios supeditados a los intereses de capital" (Corral, 2009, p. 4). En el caso de Puerto Madero se destaca, como la reconversión del puerto tenía un interés prioritario de "atraer inversiones y generar nuevas actividades económicas". Lo anterior influyó directamente en la transformación de los usos del suelo para la zona, los cuales incluían un mix de actividades, incorporadas aquellas dirigidas al consumo, especialmente a grupos de altos ingresos, actividades escolares y de construcción de viviendas (urbanizaciones). "La reconversión implicaba un reordenamiento del área que buscaba otorgar un carácter urbano a la misma” (Corral 2009, 7). 
FIGURA 2. PUERTO MADERO
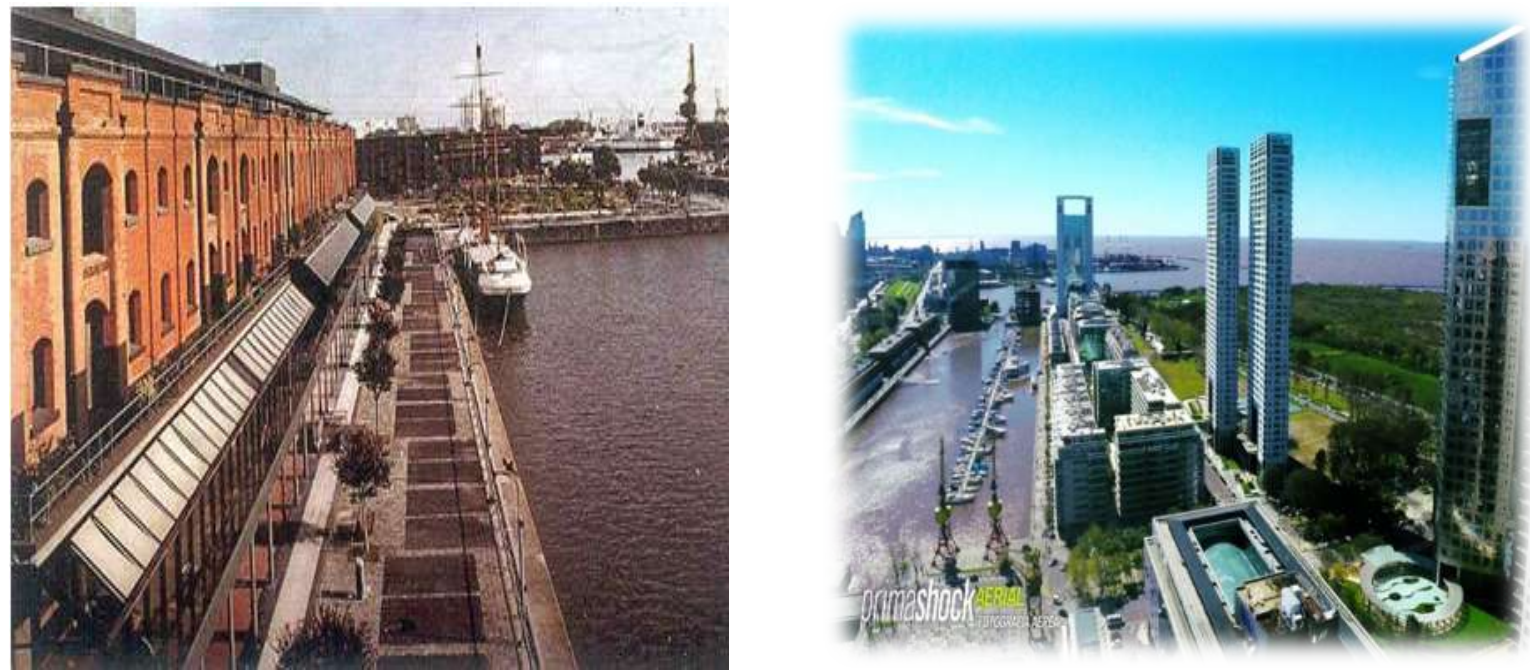

Fuente: Google Imágenes/ http://www.rafaellopezrangel.com

FIGURA 3. USOS DEL SUELO PUERTO MADERO

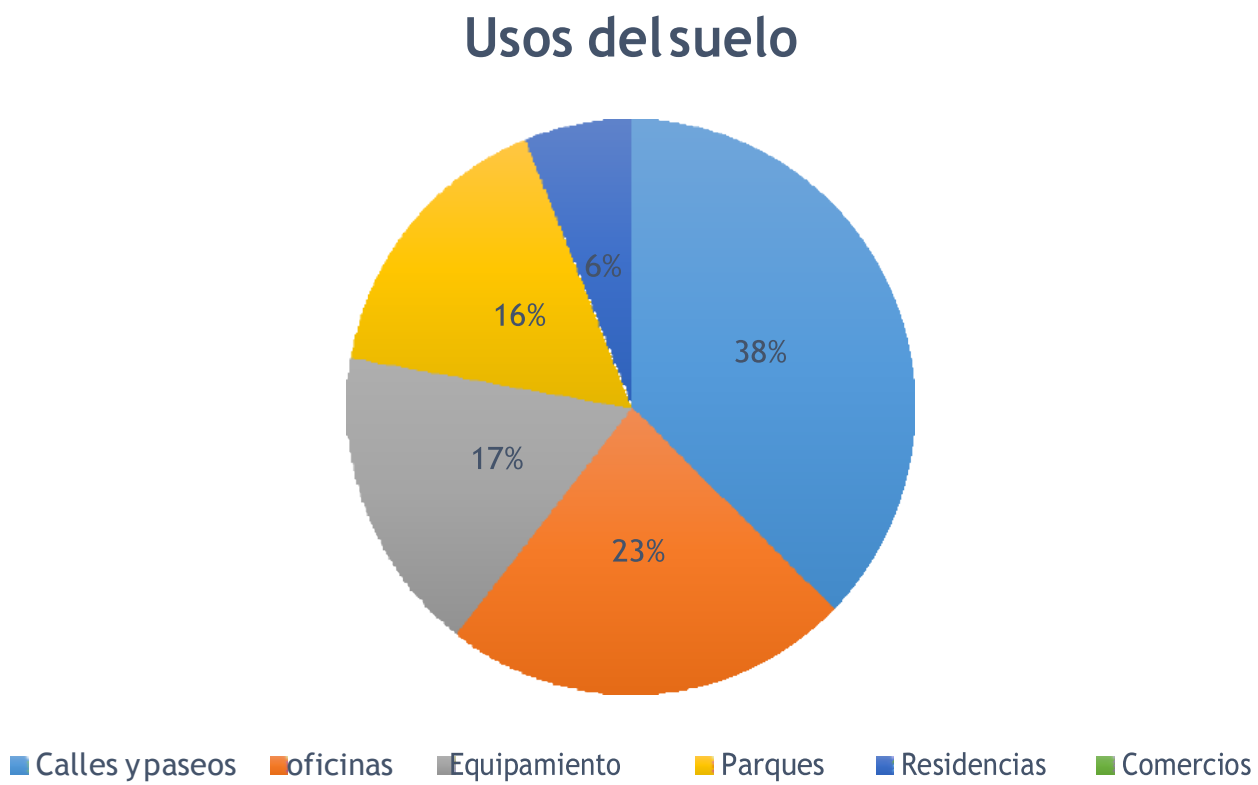

Fuente: Corral. (2009).

Valorización del suelo: en este aspecto Corral (2009), se apoya en la hipótesis de Cuenya (2011) que a su vez sustenta la hipótesis del presente análisis: "este tipo de proyectos se localizan habitualmente en zonas que han quedado relegadas y por lo tanto su valor de partida del suelo es bajo, pero su valor final es 
muy alto dada su extensión, su localización estratégica y la alta calidad edilicia y simbólica de lo que se construye allí, es decir, se localizan en zonas que son consideradas "áreas de oportunidad" (Cuenya, 2011). En este aspecto Corral destaca que para el caso del puerto, se dio una transformación funcional del área, lo cual permitió que esta se incorporara nuevamente al área central (Corral, 2009, p. 9), la selección de esta área, estuvo muy relacionada con las ventajas en términos de accesibilidad y localización que conservaba la zona:
En el caso de Puerto Madero se trata de una zona muy próxima al área central y por lo tanto con una importante accesibilidad. Asimismo, y como ya mencionamos, se trata de un área extensa de 170 ha. Estas características permiten una rápida valorización del suelo una vez que se ha realizado la inversión en infraestructura. Por otra parte, en este tipo de proyectos y específicamente en el caso aquí trabajado favorece dicha valorización la calidad de los materiales y la incorporación de tecnologías utilizadas en los emprendimientos realizados, así como la existencia de elementos con un alto valor simbólico. (Corral, 2009, p. 9).

\section{CUADRO 2. VARIACIONES EN EL VALOR ${ }^{2}$ DE USOS DEL SUELO EN PUERTO MADERO}

\begin{tabular}{|c|c|c|}
\hline Año & Valor por promedio del $\mathbf{m t}^{\mathbf{2}}$ & Incremento \\
\hline 2005 & 2647 & \\
\hline 2006 & 2729 & 4.00 \\
\hline 2007 & 3085 & 13.04 \\
\hline 2008 & 3744 & 21.36 \\
\hline
\end{tabular}

Fuente: Corral. (2009).

Según Corral (2009), existen 3 factores que impulsan el aumento del valor del suelo en la zona intervenida por el G.P.U: “1) La proximidad al área céntrica, 2) la seguridad del barrio brindada por el gobierno local y 3) el alto nivel de construcción de diversos proyectos en la zona" (p. 11). En el caso de Puerto Madero la autora recalca la participación directa del gobierno nacional y local, específicamente en la construcción de infraestructura y proyectos que permitieron la valorización del área del puerto y las zonas aledañas, el Estado fue un actor promotor del desarrollo y la inversión en Puerto Madero.

Lo planteado hasta este punto, permite inferir que en los casos de G.P.U de tercera generación, se pone de manifiesto una actuación activa por parte

\footnotetext{
${ }^{2}$ En dólares. Datos en base al reporte de valor inmobiliario.
} 
de los actores políticos, específicamente del Estado o gobierno local. Citada actuación no solo promueve la construcción de los proyectos y la ocupación de áreas centrales abandonadas a partir del crecimiento urbano, sino que a su vez el Estado, impulsa la participación de los actores privados, ya sea con incentivos en la reducción de impuestos o con el aumento de inversiones a infraestructura urbana en la zona a intervenir, Para el caso de Puerto Madero en torno a la relación del gobierno local desde la figura de lo público, con el sector privado, es posible identificar una alianza públicoprivada que se materializó con la creación de la empresa urbanizadora Corporación Antiguo Puerto Madero S.A, la cual aunque fue creada por el Estado mismo, "no estaba regulada por una ley nacional que controle a las sociedades comerciales privadas y por ende no le correspondía informar sobre el manejo de sus recursos" (Cuenya y Corral 2011, p. 34).

Otro aspecto a destacar en la actuación del gobierno local en el caso puerto madero es su objetivo de impulsar lo que las autoras han denominado "promoción económica del lugar sin redistribución del excedente" (Cuenya y Corral, 2011), este proceso está muy anclado al propósito de potenciar el lugar y también se encuentra asociado a la necesidad de convertir el área en foco de interés para la inversión y el desarrollo urbano, aun en detrimento de intervenir con obra pública otras áreas de la ciudad. Estas actuaciones son características de la gobernanza de corte empresarialista:

La cultura del empresarialismo tiene ciertos aspectos claves:1). La asociación entre lo público y lo privado; 2). la actividad de esa parte pública-privada es emprendedora precisamente porque es especulativa, en la ejecución y diseño y, por lo tanto, perseguida por las dificultades y peligros especulativos en contraposición a planificar racionalmente un desarrollo coordinado. En pocas palabras el sector público nunca asume la mayor ganancia pero si asume el mayor riesgo. 3). el espíritu del empresarialismo se centrara más en la política de lugar por encima de la política del territorio, en esta medida las mejoras en las condiciones de vida de los pobladores se limitaran a la mejora de espacios determinados donde se potencie la inversión en grandes proyectos urbanos. (Harvey, 1989, p.12). 


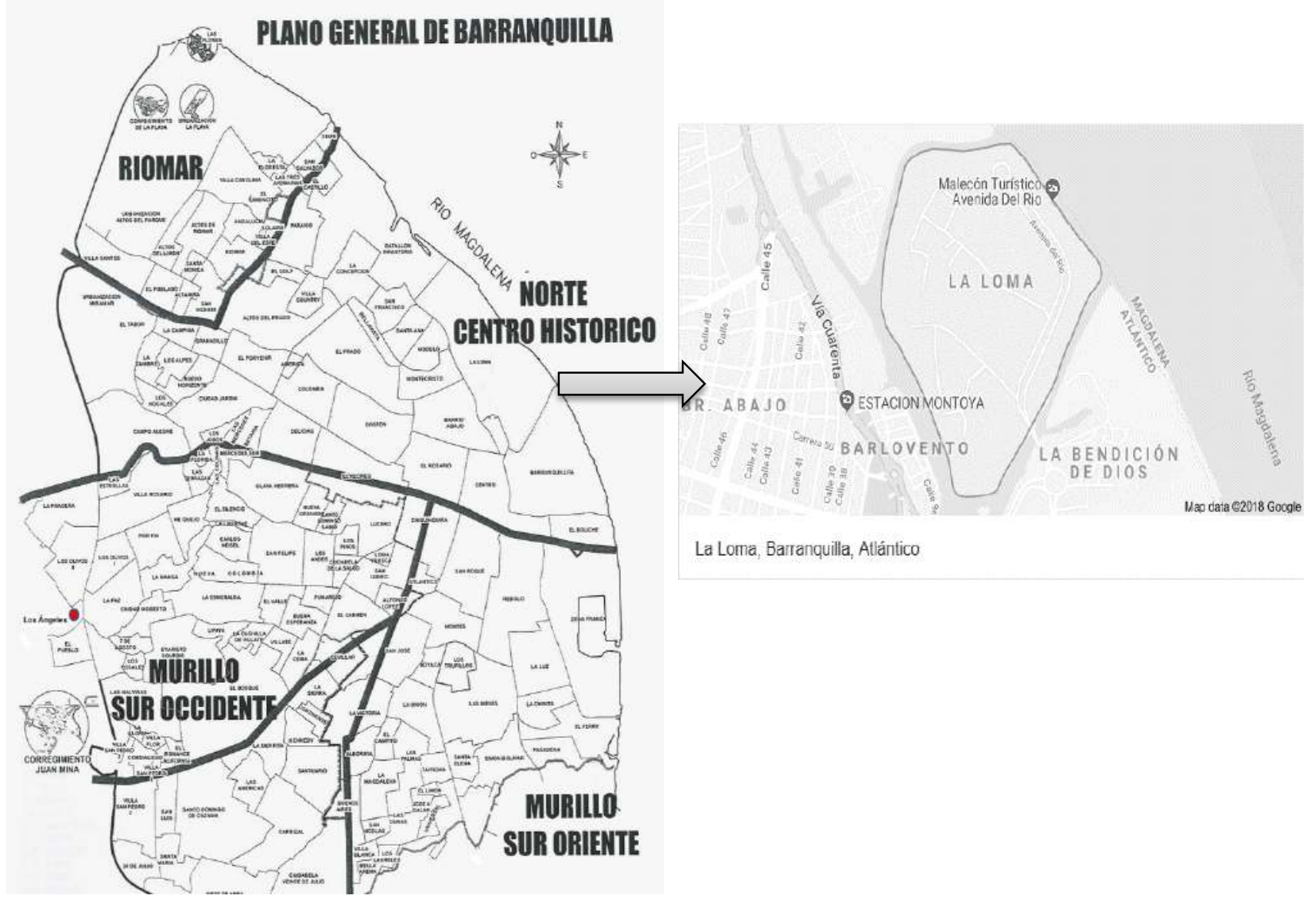

Fuente: Google Imágenes, Maps.

\subsection{La Loma: Barranquilla}

El gran proyecto urbano La Loma actualmente se encuentra en ejecución en los terrenos de la isla La Loma en la ciudad de Barranquilla, esta isla está ubicada a orillas del Rio Magdalena en la localidad Norte Centro Histórico de Barranquilla. La ventaja localizativa que caracteriza a la isla le convierte en un bien preciado para potenciar la renovación del área histórica e impulsar la "vuelta al Rio" un proyecto que ha tomado como bandera la administración local de los últimos 12 años en la ciudad: "Volver al río, un sueño hecho realidad. Es el proyecto urbanístico más importante en la historia de la ciudad y no tendrá estratos" (Noguera, 2014). En el área de la isla La Loma la Alcaldía de Barranquilla en asocio con el mercado inmobiliario, constructoras Amarilo, Constructora Bolívar, Marval, Prodesa, Constructora Colpatria y el sector financiero, ejecutan el que según fuentes oficiales 
de prensa es el proyecto urbanístico más grande e importante de la ciudad y que pretende convertirse en el eje de desarrollo económico de la Región Caribe. El proyecto la Loma está constituido por 96 hectáreas, en su interior se construirá la nueva sede de la Alcaldía de Barranquilla, un $45 \%$ de las áreas del proyecto estarán destinadas a espacios residenciales -3.500 apartamentos- comerciales y áreas destinadas a servicios y consumo; un $55 \%$ del área del proyecto estará destinada a espacios públicos con la construcción de vías, parques, plazas, plazoletas, malecones, un circuito turístico y ciclorrutas (Herrera, 2018).

Este gran proyecto urbano, que tiene dentro de sus objetivos contribuir a la reactivación económica del Centro Histórico y al aumento de la competitividad de la ciudad a partir del impulso de su dinamismo local, regional, nacional (Herrera, 2018), se categoriza como un G.P.U de tercera generación, ya que al igual que en el caso de Puerto Madero, plantea esencialmente un proceso de renovación en el área del centro histórico, sustentado en intereses económicos y políticos, especialmente relacionados con el fortalecimiento de la inversión y el capital inmobiliario en la ciudad. Este proyecto ha sido posible gracias a una fuerte inversión (local/regional/na- cional) en infraestructura, lo que según fuentes de la administración Distrital "potenciara la reactivación económica de la ciudad, convirtiéndole en eje del desarrollo económico en la región Caribe" (Portafolio, 2014).

A su vez, el proyecto La Loma se sustenta sobre la base de una deuda histórica que la ciudad de Barranquilla presenta con el río, tras haberse construido a espaldas del mismo. Este aspecto histórico y en cierta medida "identitario de la génesis de Barranquilla", ha permito que la administración local, desde la alcaldía de Elsa Noguera (2012-2015) abandere el proceso para volver la ciudad al río y encaminar todo el desarrollo urbano hacia la reconfiguración de la relación ciudad-río (Entrevista a Elsa Noguera, El Heraldo, 2014).

El proyecto La Loma sin embargo, no responde a un interés específico del gobierno local de turno, debido a que desde los años 9o's la administración del alcalde Edgar George (1995-1997) planteó la necesidad de intervenir ciertas zonas del centro histórico de la ciudad, a partir de un proceso de renovación urbana enmarcado en el "Plan Estratégico del Distrito Especial, Industrial y Portuario de Barranquilla", tales zonas incluían: el sector de Barranquillita y el Boliche (Decreto 629 de 1994). Más adelante en el año 2005, el alcalde de turno Guillermo 
Hoenigsberg, emite el Decreto 0123, en el que se crean tres planes parciales para la recuperación del centro histórico, entre los cuales se encuentra el G.P.U La Loma. No obstante, estos proyectos solo quedaron en el papel y fueron muy escazas las políticas y proyectos que focalizaran y destinaran presupuesto del gobierno nacional y local para su ejecución, no es sino hasta 2012, con el plan de gobierno de la alcaldesa Elsa Noguera, que se incluye un apartado específico destinado a la renovación de la zona céntrica de la ciudad:

- Barranquilla Competitiva: En este eje se reúnen estrategias, programas y proyectos que mejoran la seguridad y convivencia ciudadana, la infraestructura de comunicación física y virtual, los equipamientos y la optimización en los procesos y trámites necesarios para la creación, formalización, consolidación y desarrollo de las actividades empresariales, y lograr la oferta de una fuerza laboral competente que responda a los requerimientos de la ciudad y la región.

\section{- Programa de Desarrollo Urbanís-}

tico: Emprender proyectos de desarrollo urbanístico en el sector de la Loma es una de las prioridades de la administración y para la ciudadanía que tiene fundadas expectativas en el retorno a uno de los sectores que brinda mayores posibilidades a los ciudadanos y a los inversionistas nacionales y extranjeros. Se espera culminar un proceso que recupera un sector estratégico de la ciudad, habilitado para emprender proyectos productivos, sociales y culturales. (Plan de gobierno Elsa Noguera, 2012-2015).

\section{- Artículo 22. Estrategia El Centro} Histórico Renovado, un polo de desarrollo: Incentivar su renovación urbana y arquitectónica, aumentando la seguridad, ordenando el comercio, despejando el espacio público y generando normas que atraigan la inversión privada para que revitalice esta zona bicentenaria. Transformarlo en un lugar estratégico para la coexistencia de la economía y la historia de la ciudad, para que se convierta en zona turística, residencial y de negocios. (Plan de Gobierno Elsa Noguera, 2012-2015).

Conforme a los lineamientos de la Ley 388 de 1997 y a sus Decretos Reglamentarios 2181 de 2006 y 4065 de 2008, El Distrito de Barranquilla, ha venido trabajando en la ejecución del Proceso de Renovación Urbana del área central de la ciudad a través de Plan Especial de Manejo y Protección, logrando importantes avances. (Plan de gobierno Elsa Noguera, 20122015).

A partir de estos acápites del plan de desarrollo, el gobierno Distrital da 
inicio al marco legal que sustenta la renovación urbana del centro histórico, cuyo eje focal de desarrollo estaría representado por el macroproyecto: La Loma. A su vez la administración local, durante el periodo de Elsa Noguera, llevo a cabo la inversión en infraestructura y recuperación de edificios patrimoniales, que representaban la puesta en marcha del macro proyecto: reubicación de vendedores de San Andresito y construcción del monumento en homenaje a Gabriel García Márquez; construcción de la avenida del rio, obras de mejoramiento de vías y construcción de la conexión vial entre Barranquilla y Santa Marta; remodelación de la intendencia fluvial, entre otras contempladas a futuro, las cuales se presentan a continuación:

- Obra: renovación de la intendencia fluvial/ Inversión: 1.800 millones de pesos (El Heraldo 2014). Obra: Centro de eventos Puerta de Oro/ Inversión: 250.00o Millones de pesos (Dinero, 2016).

- Obra: reubicación de los vendedores informales de San Andresito/ Inversión:
2.400 millones de pesos (El Heraldo, 2013).

- Obra: Fábrica de la cultura/ Inversión inicial: 5.500 millones de pesos (Alcaldía de Barranquilla, 2016)

- Megaproyecto: La Loma/ Inversión inicial: 2 mil millones de pesos

- Obra: nueva sede de la Alcaldía/ Inversión: 120.000 millones de pesos (El Heraldo 2016) Obra: Portal de Transmetro en Barranquillita/ Inversión: 24.000 mil millones de pesos (Transmetro 2015); este terreno fue adquirido gracias a la reubicación del asentamiento informal "Las Colmenas" con una inversión de 4.000 millones de pesos (Polo 2013).

- Obra: Intercambiador vial del Corredor Portuario/ Inversión: 2.600 millones de pesos (De la Cruz 2014).

- Obra: nueva sede el Museo de Arte Moderno de Barranquilla/ Inversión: 12.00o mil millones (Alcaldía de Barranquilla 2015).

Obra: Par vial de la carrera 50/ Inversión: 10.150 mil millones de pesos (El Universal 2015). 
FIGURA 5. ZONA DE INTERVENCIÓN Y OBRAS DE INFRAESTRUCTURA

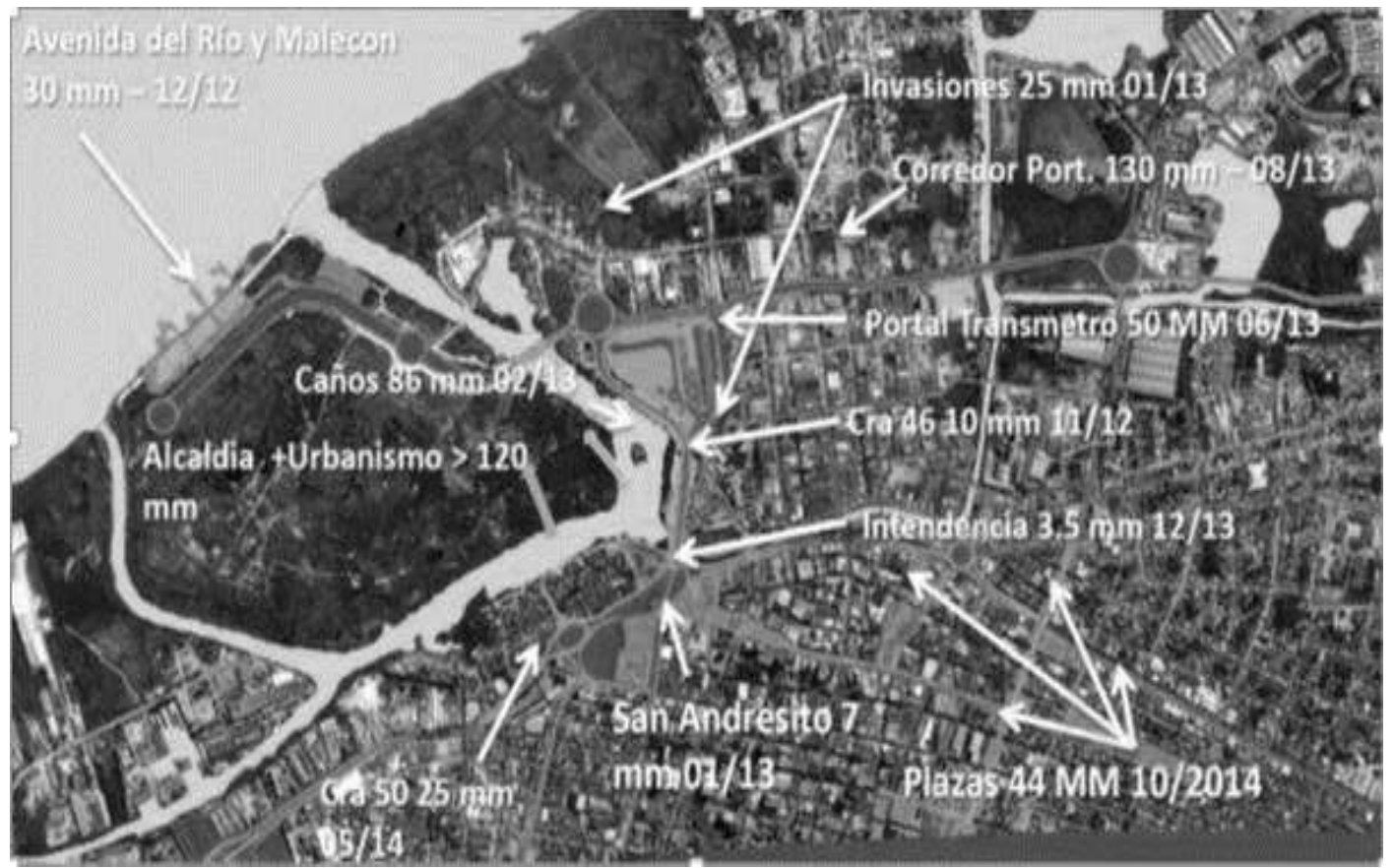

Fuente: http://www.barranquilla.gov.co/normatividad/leyes-y-acuerdos/doc_download/1686-laloma-el- proyecto-de-todos.

FIGURA 6. OBRAS DE INFRAESTRUCTURA EN EL ÁREA DEL G.P.U LA LOMA
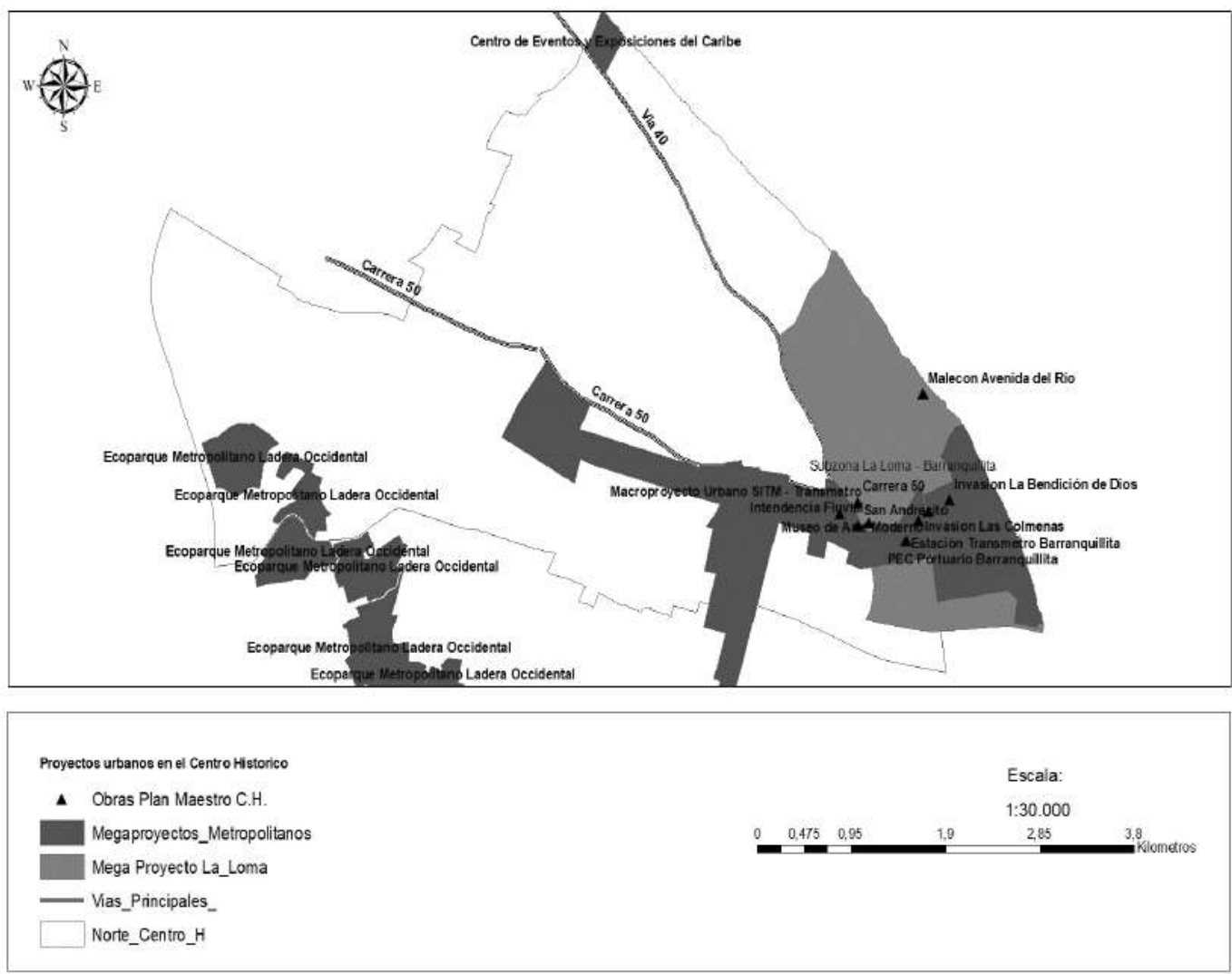

Fuente: P.O.T 2012. 
Si bien el proyecto La Loma aún se encuentra en una fase inicial de desarrollo, ya pueden destacarse algunas externalidades negativas del mismo, tal como lo evidencia el análisis preliminar de Terán (2016), quien señala algunos impactos negativos de las fases iniciales y otros posibles efectos derivados del avance del proyecto:

- Transformación y uso del suelo:

En este aspecto característico del G.P.U, el trabajo de investigación del sociólogo e investigador urbano José Terán, analiza los efectos socio-espaciales que derivan de la implementación del G.P.U La Loma. En sus análisis de la fase preliminar de implementación del mega proyecto, Terán destaca como a partir de alianzas entre el sector público y privado, la administración local a través del plan de ordenamiento territorial ha transformado los usos del suelo, especialmente en relación a la construcción áreas que propician la configuración de un espacio privatizado y excluyente (Elitización del lugar). Este aspecto es fundamental, ya que en la zona de la isla La Loma y alrededores, residian moradores de diversos barrios de invasión de la ciudad, dicha población en su gran mayoría, formaba parte de la población desplaza por el conflicto en zonas de la costa y el interior del país y sus actividades económicas estaban destinadas principalmente a la pesca y la economía informal.

Por otra parte, se afirma la existencia de un proceso de erotización de la zona, dado que el G.P.U contempla la construcción de edificios de oficinas y de viviendas para estratos 4,5 y 6 de la ciudad, de esta forma el uso del suelo se destinará a actividades de alto consumo (Terán 2016, p.6). Para ello, la administración local reglamentó la trasformación del uso del suelo, beneficiando directamente al mercado inmobiliario y a la empresa privada. En esta misma línea, El autor expone que si bien el área de la Isla La Loma, es un área categorizada como área natural, fue sometida a una transformación abrupta de su categoría de uso del suelo en el P.O.T del 2012, lo anterior a fin de garantizar la puesta en marcha del G.P.U y transformar sus condiciones naturales a condiciones aptas para la edificabilidad. En la actualidad esta transformación del uso del suelo del área natural que comprende la Isla La Loma es motivo de investigación por la Procuraduría Nacional quien abrió indagación preliminar a la exalcaldesa de Barranquilla, Elsa Noguera de la Espriella, y al exalcalde de esa misma ciudad, Alejandro Char. La medida se toma tras una denuncia presentada por el ciudadano José Raúl Rodríguez, debido a los graves daños ambientales 
y ecológicos que, asegura él, está causando la implementación del nuevo POT en el sector de La Loma en la ciudad de Barranquilla. De acuerdo con el títular del periódico El Espectador: Procuraduría abre indagación preliminar contra Elsa Noguera y Alejandro Char publicado el 23 de marzo de 2018:

Rodríguez señaló en su denuncia que mediante el Decreto 0212 de 2014 se modificó el uso del suelo en esa zona, considerada uno de los "pulmones" de la capital del Atlántico. Rodríguez también aseguró que dicho POT no se socializó ante las autoridades ambientales respectivas, como el Departamento Técnico Administrativo del Medio Ambiente. (El Espectador, 2018, p. 1).

\section{- Exclusión de la población resi-}

dente: La Fase inicial del proyecto no podía llevarse a cabo sin la expulsión de la población residente en la isla -ya que la Loma es una isla que se encuentra entre el río Magdalena y el centro de Barranquilla- en este aspecto, el gobierno local negoció la reubicación de 80 familias. Pese a lo anterior, esta compra de predios no fue ampliamente consensuada, debido a que algunas familias del sector se rehusaron a salir del territorio, primordialmente porque sus actividades sociales, culturales y económicas se encuentran ancladas a la cultura ribereña (Terán 2016). De igual forma, vecinos del Barrio Barlovento, denuncian la compra de predios a residentes de forma injusta, ya que la administración no entrega el costo real de los precios de acuerdo al valor del uso del suelo en el área y por ello han iniciado un proceso de resistencia frente a la expulsión, por medio del recurso de expropiación de los residentes tradicionales. De conformidad con lo expresado en el titular del periódico El Heraldo el 22 de noviembre de 2017 Vecinos en Barlovento se oponen a expropiación de sus predio, las víctimas del desplazamiento a causa de la ejecución del Proyecto La Loma afirmaron que :

Desde las 9 a.m. de ayer, decenas de funcionarios de la Secretaría de Control Urbano y Espacio Público de la Alcaldía de Barranquilla hicieron presencia en la calle 9 con carrera $46 \mathrm{C}$, a la orilla del caño de Las Compañías, para cumplir con la recuperación de dos bienes fiscales, de los cuales solo uno fue desalojado. En ambos predios funciona una empresa dedicada desde hace 40 años al transporte fluvial, pero de acuerdo con las proyecciones del Distrito, deberá trasladarse para dar paso a las obras de construcción y de renovación de Barlovento, así como del puente que unirá este barrio con el sector de La Loma.

No nos oponemos al desarrollo de este proyecto de ciudad y aplaudimos el progreso de Barranquilla, pero a un precio justo, fue la consigna de los propietarios del inmueble.

Es absurdo que por un predio de 700 metros cuadrados, en una ubicación estratégica frente al río Magdalena y con vocación empresarial, se pague el metro cuadrado a menos de $\$ 100.000 "$, cuestionó Lucía Avendaño, hija de la representante legal de la empresa, Esperanza Gelves. 
Ahora ellos nos quieren expropiar porque no se ha llegado a un acuerdo. Ellos aducen que se hizo una negociación, pero no sé con quién porque nosotros no hemos aceptado ese precio absurdo", agregó Avendaño ante los medios. (El Heraldo, 22 de noviembre de 2018, p. 1).

- Actuación del Estado: A partir de la revisión de los proyectos presentados por la administración local y diversos titulares de la prensa, se pone de manifiesto el rol de la administración local, la cual no solo impulsa la financiación del proyecto, sino que a su vez entrega todas las herramientas necesarias para que el sector privado invierta sin inconveniente alguno y con el incentivo de la eliminación del impuesto predial por un periodo de 10 años: "Las constructoras Amarilo, Marval, Prodesa, Colpatria y Bolívar firmaron la promesa de compraventa con el promotor de La Loma (Covein S.A.S) para adquirir 100 mil metros cuadrados de terreno urbanizable destinados a proyectos de vivienda" (El Heraldo, 23 de Septiembre de 2016, p.1).

Las cinco constructoras invertirán cerca de un billón de pesos en los proyectos de desarrollo urbano, anunciaron durante el acto. El alcalde de Barranquilla, Alejandro Char, aseguró que se construirán viviendas estrato 3, 4 y 5, que estarán exentas del pago del Impuesto Predial por 10 años. (Ob., cit., p.1) el área destinada al proyecto La Loma se potencie como como un "área de oportunidad" (Cuenya, 2011). A su vez, el gobierno local impulsa una serie de obras de infraestructura para potenciar las ventajas de localización, accesibilidad, calidad e infraestructura urbana, contribuyendo directamente a la valorización de la zona de intervención y sus áreas aledañas. Esta actuación política corresponde a las lógicas del empresarialismo urbano, el cual actúa como promotor y en esta dinámica promueve la inversión en la ciudad y la expone como un bien "Cosmetizado" que se oferta ante los interés del capital. En esta misma línea, el caso de Barranquilla es un claro ejemplo de ambigüedad al tratar de separar lo público y lo privado en términos de gestión pública, especialmente en las 3 últimas administraciones Char (2008-2011)-Noguera (2012-2015) -Char (2016-2019). En el caso de la actuación del gobierno local en los G.P.U, se observa un tipo de gestión pública de corte empresarialista, propio de las lógicas del urbanismo neoliberal. Estos factores que se observan en el caso del G.P.U La Loma son propios del empresarialismo y buscan aplicarse a las ciudades para definirlas como actores estratégicos (Jessop y Ngai-Ling 2000).

Estos incentivos por parte de la alcaldía de Barranquilla pretenden que 
De esta forma el empresarialismo urbano se enfoca en potenciar los sectores: inmobiliarios, de bienes y servicios, económicos y científicos. En el caso de Barranquilla la ambigua actuación del actor público y el privado, permite que el rol del Estado se vincule más al rol de un promotor urbano: "una ciudad empresarial persigue estrategias innovadoras distintivas que le permitan mejorar su competitividad en relación con otras ciudades, en esta medida los promotores urbanos actúan de forma que su ciudad pueda venderse como un escenario prospero de inversión" (Jessop y Ngai-Ling, 2000).

\section{CONCLUSIONES}

El presente trabajo analizó el caso de dos G.P.U en ciudades de América Latina (Buenos Aires y Barranquilla), a la luz de las fuentes de información analizadas y la literatura especializada, este análisis arroja una conclusión general y dos conclusiones específicas para cada unidad de análisis:

La conclusión general evidencia que los G.P.U en América Latina, están dirigidos primordialmente a la recuperación de la centralidad urbana, siempre que esta, haya conservado sus ventajas en términos de localización, accesibilidad y que la mayoría de su territo- rio aun corresponda a bienes patrimoniales del Estado. Estas características convierten la renovación de los centros históricos en potenciales "áreas de oportunidad" (Cuenya, 2011), las cuales no solo beneficiaran al sector público, sino que resultan sumamente atractivas a los intereses del sector privado.

En relación al rol del gobierno local en este proceso de renovación, la evidencia empírica ha demostrado que los agentes políticos locales y en gran medida el gobierno nacional, juegan un rol de promotores/vendedores, que ofertan la ciudad ante los intereses del capital privado, en especial al mercado inmobiliario. Los gobiernos locales y el gobierno nacional, invierten grandes sumas de dinero en la recuperación y construcción de nueva infraestructura (Vial, servicios, industrial, cultural) que potencia la valorización del suelo en la zona de intervención y áreas aledañas y a su vez entrega el marco legal para la reglamentación de un mix de usos del suelo. El Estado garante cede el paso al Estado promotor y los gobiernos locales juegan un papel importante, ya que utilizan el discurso de la renovación del centro, la recuperación del patrimonio y la generación de desarrollo metropolitano, para hacer cada vez más delgada la línea entre gestión pública y actores privados, es muy ambiguo determinar a 
qué tipo de interés responden los gobiernos locales.

En ambos proyectos de renovación fue posible evidenciar que bajo la modalidad de alianzas público-privadas, los agentes estatales crean corporaciones -empresas-de capital público-privado como el caso de EDUBAR en Barranquilla y la Corporación Antiguo Puerto Madero S.A en Buenos Aires. Este tipo de alianzas genera cierta ambigüedad respecto a los recursos destinados a la creación de mega proyectos ya que no es posible identificar la procedencia de los fondos que conforman las corporaciones y asi mismo estas trazan una delgada línea de actuación para el gobierno local, es imposible garantizar que fondos públicos no terminaran siendo dirigidos a proyectos privados. Por ello, otro aspecto que se constata en el análisis teórico, es la inversión de altos recursos públicos en obra pública por parte de los gobiernos locales y/o nacionales en las áreas de influencia del G.P.U. Estos recursos son utilizados para la valorización del suelo en favor del mercado inmobiliario y casi nunca retornan a las arcas del Estado, dado que las herramientas que permiten el cobro de la plusvalía urbana no son aplicadas por los gobiernos locales para este tipo de proyectos.

En el caso de Puerto Madero en Buenos Aires, si bien, en un inicio el discurso de la recuperación del centro y la necesidad de posicionarlo nuevamente como eje del desarrollo de la ciudad abanderaron el G.P.U, estas lógicas fueron transformándose al punto de ceder el mayor uso del suelo a inversores privados. En esta medida Puerto Madero se consolidó como un enclave de alto nivel, con espacios privatizados y excluyentes, a la vez que se desplazó a la población de bajos recursos que residía en pequeñas invasiones. En este caso el Gobierno Nacional y local jugaron el rol de promotores con pocos indicios de ser garantes del proceso de recuperación del área histórica.

Para el caso de La Loma en Barranquilla, si bien el proyecto se encuentra en su fase inicial, las externalidades negativas ya se han puesto en evidencia, entre las cuales las principales han sido: La expulsión de la población residente en la isla La Loma, la transformación y reglamentación del uso del suelo para dar cabida a actividades relacionadas con el consumo y la vivienda para estratos 4,5 y 6 , la inversión lo$\mathrm{cal} /$ estatal en infraestructura vial, de servicios y cultural y la modificación del uso del suelo para el área natural de la Isla La loma en el P.O.T del 2012. Barranquilla representa un caso interesante de estudio, primordialmente en lo relacionado a la actuación del gobierno local, ya que existe una 
delgada línea entre el interés público y el privado, quizá resulte impensable un empresarialismo tan manifiesto, pero el caso del proyecto La Loma cumple todas las características que vinculan al G.P.U con un tipo de gestión urbana empresarial.

\section{REFERENCIAS BIBLIOGRÁFICAS}

Aguilar, L. (2009). Gobernanza y gestión pública. México: Fondo de Cultura Económica.

Arroyo, I. (2017, 22 de Noviembre). Vecinos en Barlovento se oponen a expropiación de sus predios. El Heraldo, p. 1.

Barragan, J y De Andrés, M. (2016). Expansión urbana en las áreas litorales de América Latina y Caribe. Revista de Geografía Norte Grande, 64: 129-149.

Cabrero, E. (2000). Gerencia pública municipal. Marco de análisis estratégico para la toma de decisiones en gobiernos municipales. En Cabrero, E y Nava, G (Ed.), Gerencia pública municipal. Conceptos básicos y estudios de caso, (pp.19-90). México: Miguel Ángel Porrúa, CIDE.

Castillo, M. (2014). Mega proyecto urbano. La ciudad Bicentenario de Tecámac, México. Bitácora urbano territorial, 24, 31-39.

Corral, M. (2009). Grandes Proyectos urbanos. Actores públicos y privados en el emprendimiento Puerto Madero (19892009) (pp. 1-20). Buenos Aires: Instituto de Investigaciones Gino Germani.

Corral, M (2010). Neoliberalismo, reformas estructurales y Grandes Proyectos Urbanos: Estado y actores económicos en el Proyecto Puerto Madero. Intersticios,
4(2), 187-206.

Cuenya, B y M, Corral. (2011). Empresarialismo, Economía Del Suelo Y Grandes Proyectos Urbanos: El Modelo De Puerto Madero En Buenos Aires. EURE, 37 (111), 25-45.

Cuenya, B. (2009). Grandes Proyectos Urbanos Latinoamericanos. Aportes Para Su Conceptualización Y Gestión Desde La Perspectiva Del Gobierno Local. Cuaderno Urbano, 8 (8), 229-252.

Cuenya, B. (2011). Grandes proyectos y sus impactos en la centralidad urbana. Caderno Metrópole, 13 (25), 185-212.

De Mattos, C. (2008). Globalización, negocios inmobiliarios y mercantilización del desarrollo urbano. En M, Córdova (Ed.), Lo urbano en su complejidad. Una lectura desde América Latina, (pp. 35-62). Quito: FLACSO Ecuador, Ministerio de Cultura.

El Heraldo (2016, 23 de Septiembre). Cinco firmas comprometen proyectos por $\$ 1$ billón en La Loma. El Heraldo, p.1.

Etulains, J. (2008). ¿Gestión promocional o privatización de la gestión urbanística? Proyecto urbano Puerto Madero, Buenos Aires - Argentina. Bitácora Urbano Territorial, 12 (1), 171-184.

Harvey, D. (1989). From managerialism to entrepreneurialism: The transformation in urban governance in late capitalism. Geografiska Annaler. Series B, Human Geography, v. 71, n 1, 3-17. Recuperado de http://dx.doi.org/10.2307/490503.

Harvey, D. (2001). Espacios del capital. Hacia una geografía crítica. Madrid: Akal-

Herrera, L. (2018, 26 de Febrero). En Barranquilla, constructores miran hacia La Loma. El Tiempo, p.1.

Jessop, B, y Suma, N. (2000). Una ciudad 
empresarial en acción: en hong kong las estrategias emergentes en y para (inter)competición urbana. Los estudios urbanos, 37 (12).

Garay, A, Wainer, L, Hayley, H Y Rotbart, D. (2013). Puerto Madero Análisis De Un Proyecto. Lincoln Institute Of Land Policy, 10-16.

Lungo, M. (2005). Grandes proyectos urbanos. Una visión general. Urbana, 11 (37), 15-44.

Pradilla, E. (2014). La ciudad capitalista en el patrón neoliberal de acumulación en América Latina. Cadernos Metrópole, 16 (31), 37-60.

Ramírez, J. (2014). El Patrimonio Como Artificio Para La Renovación Urbana De Puerto Madero. Recuperado de https://elcanelazodelaciu-

dad.org/2014/05/29/el- patrimoniocomo-artificio-para-la-renovacion-urbana-de-puerto-madero-tretas-inmobiliarias-del-neoliberalismo-en-la-capital-argentina/

Ramirez, J. (2017). Puerto Madero entendido como ícono de la Buenos Aires contemporánea (1991-2012). Revista Ciudades, Estados y Política, 4 (2), pp. 4150.

El Espectador, (2018, 23 de Marzo). Procuraduría abre indagación preliminar contra Elsa Noguera y Alejandro Char.

Rofman, A. (2006). "El enfoque del desarrollo local: conflictos y limitaciones". En Rofman, A y Villar, A (Ed.), Desarrollo local. Una revisión crítica del debate, (pp. 37-58). Buenos Aires: Espacio Editorial.

Terán; J. (2016). El neoliberalismo urbano como herramienta de transformación urbana exclusiva, y excluyente en la ciudad de Barranquilla: El caso del G.P.U La Loma. Agora Flacso Andes, 1-13. Recuperado de http://www.flacsoandes.edu.ec/agora/62793-el-neoliberalismourbano-como-herramienta-de-transformacion-urbana-exclusiva-y

Terán, J. (2016). La política de city marketing de la ciudad de Barranquilla y su proyecto renovación urbana: una aproximación analítica al GPU de La Loma. Agora Flacso Andes, 1-16. Recuperado de http://www.flacsoandes.edu.ec/agora/62792-la-politica-de-citymarketing-de-la-ciudad-de-barranquilla-y-suproyecto-renovacion

Valenzuela, A. (2013). Dispositivos De La Globalización: La Construcción De Grandes Proyectos Urbanos en la ciudad de Mexico. EURE, 39 (116), 101-118.

\section{PARA CITAR ESTE ARTÍCULO:}

Martínez Girón, A. (2018). Empresarialismo y grandes proyectos urbanos: análisis comparativo de puerto madero en buenos aires y la loma en barranquilla. Collectivus, Revista de Ciencias Sociales, 5(2), 80-108.

DOI: http://dx.doi.org/10.15648/Coll.2.2018.6

Recibido: 16/02/2018 Aprobado: 08/05/2018 